\title{
Discussion on the Necessity and Measures of Mental Health Education in Senior Chinese Teaching in Primary Schools
}

\author{
Yanru Zhang \\ Graduate School \\ Jiangxi University of Traditional Chinese Medicine \\ Nanchang, Jiangxi, China \\ Zhuofan Liu \\ Graduate School \\ Jiangxi University of Traditional Chinese Medicine \\ Nanchang, Jiangxi, China
}

\author{
Huimin Song \\ Graduate School \\ Jiangxi University of Traditional Chinese Medicine \\ Nanchang, Jiangxi, China \\ Kesui Deng* \\ School of Humanities \\ Jiangxi University of Traditional Chinese Medicine \\ Nanchang, Jiangxi, China \\ 995948023@qq.com
}

\begin{abstract}
In order to promote the formation of pupils' healthy psychology, this paper mainly discussed five measures of mental health education in Chinese teaching of senior grade in primary schools and explained how these measures can be skillfully integrated with Chinese teaching in primary schools. Attaching importance to students' mental health education in the process of Chinese teaching will improve pupils' psychological health, but it takes hard work.
\end{abstract}

Keywords—mental health education; Chinese teaching; senior grade of primary school

\section{INTRODUCTION}

Mental health is an important connotation of modern health concept, a major prerequisite for primary school students to receive education and learn scientific and cultural knowledge, and an effective way for schools to carry out quality education.

With the increasing enlargement of the only-child group in China, the number of pupils with mental disorders is on the rise. According to the survey report issued by China Mental Health Association in recent years, the current mental health status of primary school students in China is worrying, and the detection rate of mental health problems is increasing with the increase of age. The government had clearly stipulated that primary and secondary schools should equip them with mental health teachers. But it's not enough for a few mental health teachers to target a school's students. This phenomenon has also been found, and the school has also increased the propaganda of mental health education as well as strengthens mental health education counseling for teachers of all subjects in the schools to improve teachers' awareness of prevention of psychological problems. In this process, we should gradually develop and improve teachers' ability of infiltrating students' mental health education in the teaching process.

\section{The NECESSITY OF MENTAL HEALTH EDUCATION IN SENIOR PRIMARY SCHOOL STUDENTS}

Students are in the early stage of puberty in the senior grade of primary school. The change of hormone level in physiology, the strengthening of self-consciousness in psychology, and the pressure of entrance examination in elementary school all lead to more psychological distress and problems in elementary school. These psychological problems will hinder students' learning and communicative activities, the formation and development of healthy personality, and the formation and development of correct world outlook and values.

“National Mental Health Guidelines” clearly pointed out: "Mental health education is to improve the psychological quality of primary and secondary school students, is an important part of the implementation of quality education." Therefore, it is necessary to strengthen mental health education in the higher grades of primary schools. As a basic subject in primary school, Chinese contains abundant humanistic feelings, perseverance, correct values and so on. All of these provide abundant materials for mental health education of students. In primary school, based on curriculum objectives, many teachers regard Chinese curriculum as a basic subject to improve students' cultural literacy, but ignore the mental health education resources contained in it[1]. So how to strengthen the mental health education of the senior primary school students in the language teaching? Next, the author will combine with teaching practice to put forward effective measures on this issue.

\section{Measures of DeVEloping Mental Health EDUCATION IN PRIMARY CHINESE TEACHING}

\section{A. To use emotional mediation method in Chinese teaching}

It is well known that children in adolescence are prone to strong and unstable emotional expressions. However, a stable mood is very important to the study and life of senior primary school students. According to the open-ended 
question-and-answer on the daily negative emotional events of senior pupils in primary schools, the results showed that the events in interpersonal communication accounted for $50 \%$ of the total negative events, learning problems accounted for $48 \%$, and entertainment negative events accounted for less, accounting for only $2 \%$. It can be seen that the senior pupils in primary school have serious problems in interpersonal communication and learning, and thus have a negative emotional experience[2].

In this case, as a language teacher, on the one hand, we should strengthen the teaching of Chinese professional knowledge, and more importantly, we should take the responsibility for mental health education. Especially in the regulation of negative emotions, we should not only guide students to deal with problems actively, but also teach students the emotional management methods to relieve negative emotions and stabilize them.

Emotional regulation can be divided into internal and external regulation according to its source. Among them, after-class writing is an effective way to express and alleviate negative emotions, which is also an effective way to improve writing ability. But this writing can no longer be presented to students in the form of homework, which becomes an invisible pressure and a greenhouse for negative emotions. Secondly, Chinese teachers can also use Chinese textbooks to spread positive and open-minded values of life, so that students can get optimistic and open-minded and other excellent qualities. In the face of negative emotions, we can regulate emotions through positive self-suggestion. For example, Su Shi's poetry Dingfeng Ba, "Don't listen to the sound of piercing the forest and beating the leaves, why not whistle and walk slowly? Who is afraid that bamboo sticks and awn shoes are lighter than horses? Rain and mist will last a lifetime. The steep spring breeze sobers up, slightly cold, but the hilltop slants to meet. Looking back on the bleak places, returning, there is no rain or sunshine.” This poem conveys the poet's open-mindedness.

\section{B. To cultivate students' frustration concept in Chinese teaching}

According to statistics, most bullying incidents in primary schools occur in the senior stage of primary school. Such incidents are caused by many factors, but one of them is that we can't ignore: the students in the upper grades of primary school will face more academic pressure and interpersonal pressure than those in the lower grades of primary school. They will also suffer more setbacks than those in the lower grades of primary school. According to frustration-aggression theory, "when a person's motivation and behavior are frustrated, there will be more attacks and violations." Therefore, in our Chinese teaching, we should pay attention to the cultivation of students' frustration consciousness, and teach students how to face the setbacks in life and study correctly. This requires teachers to make full use of effective teaching methods, pay attention to the cultivation of students' scientific frustration concepts, implement the frustration tolerance ability in the teaching contents, and guide students to face the challenges brought by frustration positively, instead of facing them with an evasive mentality[3]. For example, when we talk about the text "The Crow Drinks Water”, we should guide students to understand that when facing difficulties, we should find ways to solve problems, rather than avoid them. Students can further share their life or learning problems and solutions.

The formation of the correct concept of frustration does not take place overnight, but requires long-term guidance from teachers. Students should be allowed to recognize, experience and solve setbacks so as to form a correct concept of setbacks. The correct concept of frustration is obviously beneficial and harmless to students' physical and mental health.

To be good at using examples in the process of Chinese teaching

Under the influence of exam-oriented education, the senior pupils in primary schools generally lack enthusiasm for learning. According to observational learning in Bandura's social learning theory, we can know that human learning comes not only from direct experience, but also from indirect experience, that is, the process of acquiring behavior by observing the behavior of demonstrators. In primary school Chinese teaching, teachers' words and deeds are a hidden command and guidance for students. To a certain extent, they can affect the development and growth of students. It can be said that teachers are the most direct examples of students in learning and life[4]. Therefore, teachers must show good spiritual outlook and upward enthusiasm for learning and life in front of students.

Chinese textbooks contain a wealth of famous Chinese and foreign experts, which can serve as an example for students. Teachers should be good at using this resource for teaching. For example, Suwu in the text "Suwu Shepherd" and Yuan Longping in "Contemporary Shennong Family" can be used as examples.

In Chinese classes, there are many excellent students who can be the model of other students. The excellent qualities of these students are also worth learning. But pay attention not to overpraise a classmate all the time because that praise also needs to be balanced among students.

\section{To strengthen emotional education in senior Chinese teaching in primary schools}

Primary school students' emotional cognitive ability is in a critical period of development at the stage of senior grade. They will face more interpersonal confusion, and also in the embryonic stage of love. At this time, correct emotional education is necessary.

First of all, teachers need to strengthen the training and learning of emotional cultivation in daily life and learning, and then use their own real feelings to infect and influence students in real life and learning[5]. Whether in Chinese class or after class, teachers should treat the things around them with a kind and positive attitude. On the other hand, teachers should strengthen communication with students and understand the specific situation of each student.

Secondly, we should pay attention to excavating the connotation of textbooks and find out the lyric points of articles. In Chinese textbooks for senior primary school students, the emotional depth and complexity of many articles exceed the cognitive range of senior students in primary schools at present. 
Therefore, this requires teachers to accurately grasp the ideological and emotional of pupils at this stage, and then find out the starting point of emotional expression in Chinese articles, integrate emotional education into Chinese teaching, and strive to achieve the resonance between Chinese teaching and pupils' thoughts, so as to achieve the purpose of emotional education[6]. For example, the sixth grade text "Spear and Shield” in Peking Normal University Edition of primary school tells us that a person praises the spear and shield he sells at the same time, but he can't justify himself because of self-contradiction. This tells people to be realistic and ironic. Obviously, most of the sixth grade students in primary school can't understand the surface meaning of Han Feizi's article, let alone it's the ironic implication. This requires teachers to find the emotional tone of the article to explain.

Emotional education requires teachers to innovate teaching methods so that students can experience emotions in their own situations. There are many innovative teaching methods, such as multimedia video interpretation, role playing, situational education and so on. Teachers can choose according to the content of different articles. For example, in Wang Wei’s poem "Send Yuan Er Envoy to Xi'an", he advised the emperor to drink more wine, leaving the sun in the West for no reason. How to understand the poet's reluctance to leave, the teacher first has to explain the first two sentences of this poem, to show the parting atmosphere in a unique form. For example, let students do role-playing, let students experience such feelings of separation.

Emotional education is different from the explanation of general knowledge and needs to be gradual. Different levels of emotions need different ways of explaining education, specifically on specific issues.

\section{To promote the development of students' intelligence in senior Chinese teaching in primary schools}

Nowadays, the most important concept of psychology in Chinese educational circles is "constructivism". Constructivism opposes the simple objectivism that has dominated education for a long time. Pure objectivists believe that the world exists objectively and that knowledge is an absolutely correct reflection of the world. It can be instilled into the educated by the educator intact, so that the educated can passively understand the world by memorizing and mastering stable "objective" knowledge. It is under the control of this objectivism that many teachers regard themselves as imparters of knowledge and students as passive receivers of knowledge. Constructivists believe that knowledge is not a simple reflection of the objective external world, but a rationalization and organization of personal experience. Students' unique understanding of the world may not meet teachers' expectations, but for students themselves, this construction is meaningful. It is a subjective organization of the world based on their previous experience. Since teachers are not merely imparters of knowledge in constructivist education, what role should teachers play in the process of teaching? Constructivist teaching view holds that the meaning of knowledge lies in context, learning context is not an irrelevant factor, and students must acquire certain knowledge through specific context. Teachers should be the creators of good learning situations and students are willing to construct knowledge. By creating certain situations, teachers can make students feel knowledge, cultivate their feelings for knowledge, and then give full play to their subjective initiative to actively recognize and construct the external objective world. [7]

As mentioned above, emotional education needs innovative teaching methods, such as situational education. Situational education is also used to promote the development of students' intelligence and psychological quality in Chinese education. Because situational education emphasizes the development of intelligence as an important task of teaching. However, the core of intelligence training is to attach importance to the training of thinking quality. Language is composed of language and literature. The dialectical relationship between language and thinking is a long-term topic in the field of psychology. Therefore, situational education should be used to develop students' intelligence in Chinese teaching in primary schools.

Promoting the development of students' intelligence can help students solve the difficulties in daily learning and life, reduce the generation of negative emotions, and promote the formation of healthy psychology.

\section{CONCLUSION}

The necessity of mental health education in senior Chinese teaching in primary schools lies not only in the urgent need of mental health education among senior primary school students, but also in the close relationship between Chinese education and mental health education. Five measures should be taken to improve senior primary school students' mental health: 1) Use emotional mediation method in Chinese teaching; 2) Cultivate students' frustration concept; 3)Be good at using examples in the process of Chinese teaching; 4)Strengthen emotional education; 5)Promote the development of students' intelligence in senior Chinese teaching.

\section{REFERENCES}

[1] Sun Yan. The Effective Permeation of Mental Health Education in Chinese Teaching in Primary Schools[J]. Scholarship Weekly, 2018 (28) 91-92.(In Chinese)

[2] Zhao Fangfang, Li Xiaotong, Tang Guangrong. Research on Emotional Experience and Emotional Regulation Strategies and Counseling of Senior Primary School Students[J]. Educational Guide, 2018 (10): 47-51].(In Chinese)

[3] Yuan Ronghong. Research on infiltrating mental health education into Chinese teaching of middle and senior grades in primary schools[J]. Intelligence, 2016 (27): 153.(In Chinese)

[4] Li Fengying. Application Analysis of Motivation Teaching in Primary Chinese Teaching[J]. Reading and Writing (Educational and Teaching Journal), 2016, 13 (11): 189.(In Chinese)

[5] Lv Lizun. Research on Implementing Strategies of Emotional Education in Primary Chinese Teaching[J]. Huaxia Teachers, 2015 (11): 26-27.(In Chinese)

[6] Li Maolin. An Analysis of Emotional Education in Chinese Teaching in Primary Schools and Its Implementing Strategies[J]. Scholarship Weekly, 2016 (32): 96-97.(In Chinese)

[7] Lin Chongde, Luo Liang. Psychological Interpretation of Situational Teaching: Comments on Li Jilin's Educational Thought[J]. Educational Research, 2007 (02): 72-76+82.(In Chinese) 